\title{
miRNA a Multifaceted Diagnostic Tool for Diseases- A Mini Review
}

\author{
M Krishnaveni* \\ Department of Biochemistry, Periyar University, India
}

Submission: May 16, 2017; Published: June 14, 2017

"Corresponding author: Department of Biochemistry, Periyar University, Salem- 636 011, Tamil Nadu, India, Tel: 9894829823; Email: krishnavenim2011@gmail.com

\section{Mini Review}

miRNA are small noncoding RNA produced by cell having 20 nucleotides in length. Their synthesis is similar to mRNA's containing several miR encoding regions embedded in genes that codes for protein and are expressed as polycistronic. Most of the miRNA's are present at the fragile sites of the genome linked to cancer that are easy to break and rearrange in cancer cells. The binding of miRNA to target mRNA takes place via two modes: First method by following waston and crick binding at the regulatory region of miRNA a seed region near the $5^{\prime}$ end of a miRNA and this region suppress the target mRNA without any complete base pairing at the 3' end of the miRNA. Second type of binding involves improper base pairing at the $5^{\prime}$ end of miRNA. The miRNA regulatory mechanism is highly complicated as mRNA is having several binding sites for miRNA. Likewise, different miRNA are able to bind to single mRNA. miRNA are mostly regulated by DNA methylation, oxygen intake, diet, hormonal changes. They control gene expression by binding to 3' untranslated regions of target mRNA causing degradation of mRNA. They regulate nearly $30 \%$ of human genome especially genes linked to apoptosis, proliferation, differentiation, metastasis, senescence, metabolism, signal transduction. The significance of miRNA was studied during 1993. They are present in tissues, its characteristics are tissue specific, stable and resists RNA degradation. Methylation of miRNA genes depend on the sex, age, lifestyle of a person. Habits like cigarette smoking, alcohol consumption which inturn causes dysregulation of miRNA leading to the development of head and neck cancer. Hypermethylation in the promoter part of miRNA brings reduction in miRNA expression/silencing of miR leading to poor prognosis of cancer as well as angiogenesis. Fairly stable circulating methylated miRNA's in blood, urine, tears, saliva, seminal fluid, cerebrospinal fluid, extracellular fluids serve as a marker in the diagnosis, prognosis, monitoring treatment, evaluation of recurrence of tumor and also effective in eliciting immune response. Other factors that influence are histone modification especially trimethylation of histone H3 lysine 4, mitochondrial damage. Extracellular miRNA from normal and tumor cells act as a mediators in the signaling pathway especially paracrine or endocrine signaling $[1,2]$.

Normal or unaltered cellular growth, proliferation, differentiation, cell death occurs through regular miRNA transcription, processing and its binding to target mRNA leading to reduced expression of target gene by blocking protein translation. Usually, miRNA's do not require correct complementarity for target identification. Hence, a single miRNA could regulate multiple mRNA. While deletion of miRNA due to defective biosynthesis, that function as a tumor suppressor causes tumor formation, angiogenesis, antiapoptosis, undifferentiated tissue. The reverse happens with oncogenic or oncomir miRNA which are expressed enormously, when they are not required or sometime it might get expressed in wrong tissues. Generally, absence of miR in certain cases cause loss of regulation and increased $\mathrm{Bcl} 2$ possessing antiapoptotic function by blocking cytochrome c release, a prerequisite for caspases dependent cell death. miRNA is very well related to p53 a transcription factor which activate both apoptosis and regulates cell cycle. p53 activates the expression of several miRNA and aids its maturation. miRNA both positively and negatively regulates p53. In addition to this, the metabolic target of p53 are glycolysis, mitochondrial respiration. Under normal conditions, the p53 levels will be low and on stress response, activation and accumulation of p53 takes place. This active p53 binds to p53 responsive element of DNA sequence of many genes to control their expression. miRNA too regulate the stability of wild type p53 protein during stress through E3 ubiquitin ligase Mdm2. miRNA targeting Mdm2 releases p53 from Mdm2 ubiquitination, proteosomal degradation so as to maintain basal level of p53. While mutant p53 lacks its ability to induce Mdm2 transcription therefore not able to maintain basal levels of p53 via Mdm2.

The miRNA whose functions are regulated by p53 are miR 16 and miR 26a. Deletion in miR 26a encoding region causes lung, renal, breast cancer. Similarly, miR 16 causes prostate, non small 
lung cancer. Both miR-16 and miR 26a depresses cyclin D2 and E2 and induces G1 arrest invitro studies of human liver cancer cells. Apart from this, these two miR also regulates kinases involved in cell cycle thus stops the cell at G1 followed by apoptosis. The mir15a and 16-1 cluster of miRNA is deleted or reduced in chronic lymphocytic leukemia, prostate, pituitary adenoma, gastric cancer and said to control cancer via G1 phase arrest through CDK1,2 , cyclin D1, D3, E1.1 miR 34a arrests cell cycle by reducing cyclin D1 and CDK6 expression. Because increased expression of cyclin and cyclin dependent kinases leading to the phosphorylation of pRB thereby releasing E2F factors for the progression of G1 phase and also to enter into S phase. miR 99a also suppresses tumor growth by inducing cell cycle arrest at G1 phase.2 Increased Akt signaling pathway causes proliferation of cell, survival, angiogenesis, cancer. But PTEN (Phosphatase and tensin homolog) regulates Akt and thus acts as a tumor suppressor. Considering the advantages of miRNA, miRNA profiling is essential in the identification of disease states as it could diagnose the histologically non-dignostic cancers into a diagnosable cancer. Northern blot analysis, real time PCR, gene chip, microarray techniques, bead based flow cytometry are applied in miRNA profiling of normal and cancerous tissue. And at least 200 genes of miRNA is required to group human cancers based on their embryonic lineage which helps in the follow up of treatment regime of cancer. Proper research is required to over express miRNA that are used as tumor suppressors and also to suppress/inactivate miRNA in cancers. To overcome resistance in miRNA therapy, by adopting a combined miRNA therapy.

\section{References}

1. Bonci D, Coppola V, Musumeci M, Addario A, Giuffrida R, et al. (2008) The miR-15a-miR-16-1 cluster controls prostate cancer by targeting multiple oncogenic activities. Nat Med 14(11): 1271-1277.

2. Li Cui, Hua Zhou, Hu Zhao, Yaojun Zhou, Renfang Xu, et al. (2012) MicroRNA-99a induces G1-phase cell cycle arrest and suppresses tumorigenicity in renal cell carcinoma. BMC Cancer 12: 546.

\section{Your next submission with Juniper Publishers will reach you the below assets}

- Quality Editorial service

- Swift Peer Review

- Reprints availability

- E-prints Service

- Manuscript Podcast for convenient understanding

- Global attainment for your research

- Manuscript accessibility in different formats

( Pdf, E-pub, Full Text, Audio)

- Unceasing customer service

Track the below URL for one-step submission https://juniperpublishers.com/online-submission.php 